\title{
IMPACTOS DA IMPLEMENTAÇÃO DO LEAN MANUFACTURING NA OBTENÇÃO DE VANTAGEM COMPETITIVA: UM ESTUDO DE CASOS MÚLTIPLOS
}

\section{IMPACT OF THE IMPLEMENTATION OF LEAN MANUFACTURING IN OBTAINING COMPETITIVE ADVANTAGE: A MULTIPLE CASE STUDY}

\author{
Marcelo Macedo ${ }^{1}$; Edson Possamai ${ }^{2}$ \\ ${ }^{1}$ Universidade Federal de Santa Catarina- UFSC - Florianópolis - Brasil \\ marcelomacedo@egc.ufsc.br \\ ${ }^{2}$ Instituto Superior Tupy - IST/Sociesc - Joinville - Brasil \\ edson.possamai@sociesc.org.br
}

\begin{abstract}
Resumo
Numa economia globalizada, a sobrevivência das organizações depende da habilidade $e$ flexibilidade para inovar e efetuar melhorias contínuas. Nesse contexto, as organizações buscam novas ferramentas de gerenciamento, que as direcionem para uma maior competitividade através da qualidade e produtividade. Uma dessas ferramentas é o Sistema de Produção Enxuta, conhecido como Lean Manufacturing. Neste trabalho, é desenvolvido um estudo com o objetivo de analisar os impactos da implementação do Lean Manufacturing na obtenção de vantagem competitiva em duas empresas do setor moveleiro. Para atingir o objetivo proposto, foi desenvolvida uma pesquisa de do tipo qualitativa de cunho fenomenológico nas empresas Artefama e Rudnick localizadas na região de São Bento do Sul. Os principais resultados obtidos na pesquisa foram: na visão estratégica, as semelhanças que foram consideradas de maior relevância segundo os diretores entrevistados são o comitê Lean, a qualidade na fonte e a implantação das ferramentas Lean, por estarem relacionadas com todos os critérios de vantagem competitiva apresentado por Slack (1993). A consultoria, o aumento da produtividade, redução do lead time, também foram bem conceituadas na visão da direção, relacionando-se com velocidade, confiabilidade e flexibilidade. $\mathrm{Na}$ visão operacional, as semelhanças de desenvolvimento de novos produtos e melhor imagem da empresa impactam na obtenção da vantagem competitiva por oferecer mais flexibilidade produtiva $e$ dar confiabilidade ao mercado. Todas as semelhanças da perspectiva de aprendizado $e$ crescimento foram relacionadas com a qualidade e todas as melhorias realizadas na perspectiva financeira foram relacionadas com custos, segundo os funcionários. Conclui-se, portanto, que algumas ferramentas lean impactam significativamente na obtenção de vantagens competitivas.
\end{abstract}

Palavras-chave: lean manufacturing; vantagem competitiva; BSC.

\section{Introdução}

Segundo Soares (2007) as organizações buscam vantagens competitivas através da implementação de iniciativas como: incremento de qualidade total, produtividade e prestação de 
serviços aos clientes. Em grande parte dos casos, a cúpula administrativa é que possui responsabilidade por essas iniciativas. No entanto, esses administradores muitas vezes se decepcionam com os resultados alcançados. Segundo o autor, esses resultados obtidos conduzem as empresas mais à sobrevivência do que a obtenção de qualquer vantagem competitiva, "pois produtividade, qualidade e bom atendimento ao cliente são necessidades competitivas e não vantagens, daí a razão de muitas empresas terem introduzido essas iniciativas e terem feito poucos progressos" (SOARES, 2007, p.22).

A partir da aplicação dos conceitos da filosofia da produção enxuta em empresas japonesas do setor automotivo é que os conceitos relacionados a necessidade de obtenção de vantagens competitivas foram melhor compreendidos (JAMES-MOORE e GIBBONS, 1997). Princípios propostos pela manufatura enxuta têm seus conceitos difundidos em organizações pelo mundo e muitos deles têm suas origens baseadas nos estudos pioneiros de Taylor (WOMACK, 1992).

Para obter um diferencial e se posicionar de forma competitiva no ambiente globalizado, as organizações têm feito investimentos em recursos e processos de manufatura em busca da melhoria contínua. Segundo Ohno (1988), o modelo utilizado pela Toyota de manufatura enxuta, tem como base a eliminação dos desperdícios. Para autores como Shingo (1996), Womack e Jones (1996), Hines e Taylor (2000) os desperdícios podem ser classificados em: superprodução, espera, transporte excessivo, processos inadequados, estoques desnecessários, movimentação e produtos defeituosos. Como práticas e técnicas para eliminar os desperdícios podem ser citadas algumas consideradas as mais praticadas e com maiores impactos nos resultados. São elas: mudanças de layout, células de manufaturas, fluxo contínuo de peças, dispositivos a prova de falhas, troca rápida de ferramenta, mapa de fluxo de valor e muitas outras.

Há, portanto, um aumento crescente da necessidade de estruturas organizacionais mais enxutas e flexíveis visando a obtenção vantagem competitiva. Nesse contexto, com o intuito de colaborar com a construção de um referencial para análise do aporte de um sistema de produção enxuta nas empresas, específico para empresas do setor moveleiro, o objetivo do presente trabalho é analisar os impactos da implementação do Lean Manufacturing para a obtenção de vantagem competitiva em duas das principais empresas do setor moveleiro do planalto norte de Santa Catarina: Artefama e Rudnick.

O artigo está estruturado da seguinte forma: após a introdução apresenta-se a justificativa da pesquisa. Na seção três descreve-se o procedimento metodológico. Nas seções quatro, cinco, seis e sete são abordados os temas Lean Manufacturing, vantagem competitiva, relação entre Lean Manufacturing e vantagem competitiva e, fundamentos do Balanced Scorecard respectivamente. $\mathrm{Na}$ seção oito e nove apresenta-se a análise geral dos resultados da pesquisa com a empresa Rudnick e Artefama. Na seção dez analisa-se como o Lean Manufacturing pode impactar a 
obtenção de vantagem competitiva nas empresas Artefama e Rudnick. E, por fim, são feitas as considerações finais.

\section{Justificativa}

Segundo Prado e Prado (2007), o segmento moveleiro é considerado um dos mais representativos e importantes setores de transformação industrial do país. As empresas moveleiras são privilegiadas, pois, o principal insumo utilizado na transformação de móveis é a madeira, matéria-prima existente em abundância no território nacional.

O processo produtivo do setor moveleiro contempla atividades manuais e semi-automáticas, demandando uma grande quantidade de mão de obra e, consequentemente, contribuindo para o aumento na geração de riquezas e incremento da economia. A tecnologia está presente também no setor moveleiro, de forma flexível em suas linhas produtivas e contribuindo para a inovação em design, proporcionando vantagem competitiva e favorecendo o aumento nas exportações (PEREIRA, 2006).

Apesar do setor de móveis estar espalhado por todo o país, a maioria das empresas do ramo está concentrada em alguns pólos importantes como: São Paulo (SP), Bento Gonçalves (RS), São Bento do Sul (SC), Arapongas (PR) e Ubá (MG). Por outro lado, as exportações se concentram em dois pólos: São Bento do Sul (SC) e Bento Gonçalves (RS) (GARCIA e MOTTA, 2007).

O segmento moveleiro, entretanto, tem enfrentado turbulências devido a crise cambial, obrigando as empresas a se adaptarem à novas situações do mercado. Neste ambiente, há necessidade de melhorar processos, aumentar a produtividade, reduzir custos e melhorar a qualidade, para que as empresas do setor de móveis busquem modelos de gestão de produção que auxiliem no processo de adaptação às mudanças. Porter (1999) é enfático em relação a esta questão: para manter a competitividade industrial neste cenário, as empresas precisam inovar e aprimorar suas técnicas utilizando modelos de gestão que favoreçam sua vantagem competitiva.

Com clientes cada vez mais exigentes no que se refere à inovação, à entrega, à qualidade, aos prazos e, principalmente, aos preços dos produtos e serviços, as empresas precisam ter flexibilidade em sua produção e buscar, continuamente, o aumento da produtividade, eficiência e melhoria contínua de seus produtos e serviços, em meio a um mercado cada dia mais competitivo, em meio à concorrência (FARIA; VIEIRA; PERETTI, 2012).

Nesse sentido, o Lean Manufacturing propõe a utilização de um conjunto de ferramentas que podem auxiliar também as organizações do setor moveleiro a se manterem competitivas nos mercados em que atuam. Entre essas ferramentas pode-se citar: produção puxada, melhoria contínua, produção em células, nivelamento da produção entre outras (SHAH e WARD, 2003). A filosofia Lean configura-se, então, como uma importante ferramenta para obter a satisfação do 
cliente, aumentar a produtividade e melhorar da qualidade de produtos, atuando em atividades que não agregam valor e eliminando desperdícios.

"Na literatura sobre Lean existe um questionamento do Lean como panacéia (OLIVER et al, 1996; BAMBER; DALE, 2000; LEWIS, 2000). Portanto é necessário a avaliação da contribuição do Lean com o aumento da competitividade das empresas" (DIAS; FERNANDES; FILHO, 2008, p. 2). Daí a importância deste estudo, pois se vivencia um contexto onde a implementação da produção enxuta pode impactar de forma significativa no aumento da produtividade e da qualidade, proporcionando a vantagem competitiva que as organizações do setor moveleiro da região de São Bento do Sul (SC) estão buscando em período de crise.

\section{Procedimento metodológico}

Trata-se de uma pesquisa de cunho fenomenológico, do tipo qualitativa de casos múltiplos, e quanto aos objetivos, a pesquisa caracteriza-se como exploratória e descritiva. Para atingir o objetivo da pesquisa serão selecionados dois casos. Segundo Roesch (1999), estudos de casos múltiplos abrangem a comparação de diversos casos por meio da comparação de disparidades ou similaridades entre as unidades pesquisadas, como é o caso desta pesquisa. Yin (1994) sugere para este tipo de pesquisa o número de dois a três casos. Neste trabalho são analisados dois casos.

Para analisar os impactos da implementação do Lean Manufacturing para a obtenção de vantagem competitiva nas empresas Artefama e Rudnick, a realização deste trabalho segue algumas etapas. São elas:

a) Primeiro, iniciou-se uma revisão bibliográfica, buscando contemplar a literatura que trata sobre o tema Lean Manufacturing, vantagem competitiva e Balanced Scorecard (BSC). Estes temas constituem a fundamentação teórica da pesquisa;

b) $\mathrm{Na}$ sequencia elaborou-se um questionário visando obter informações relacionadas à implementação do Lean Manufacturing nas empresas estudadas. Esse questionário possui perguntas específicas relacionadas ao Lean, agrupadas separadamente dentro de cada um dos quatro indicadores do BSC: aprendizado e crescimento, processos internos, clientes e financeiro;

c) Numa próxima etapa, foram realizadas as entrevistas semi-estruturadas com diretores e funcionários de cada uma das empresas estudadas utilizando o questionário como base para obtenção de informações;

d) Adiante, foram listados os resultados das entrevistas realizadas com a direção das empresa (visão estratégica); e os resultados das entrevistas realizadas com os funcionários das empresas (visão operacional) Artefama e Rudnick. 
e) Numa etapa seguinte foram listadas as principais semelhanças existentes entre as empresas sobre as informações de implementação do Lean Manufacturing, relacionadas a cada um dos indicadores do BSC, em nível estratégico e operacional;

f) Em seguida foram determinados os critérios de obtenção de vantagem competitiva descritos por Slack (1993), e realizada uma relação desses critérios com as informações obtidas sobre a as principais semelhanças na implementação do Lean Manufacturing dentro de cada um dos quatro indicadores do BSC: aprendizado e crescimento, processos internos, clientes e financeiro;

g) E, por fim, foram realizadas as análises dos resultados a partir dos conceitos de vantagem competitiva de slack (1993) e do discurso dos entrevistados. Realizou-se uma análise cruzada dos dois casos estudados, visando identificar as semelhanças quanto a implantação do Lean Manufacturing em cada organização a partir das perspectivas do Balanced Scorecard. As semelhanças encontradas foram consideradas características que mais se destacam nas duas empresas. A partir disso, analisou-se como o Lean Manufacturing impactou na obtenção de vantagem competitiva nos casos estudados.

\section{Lean manufacturing}

Segundo Womack (1990), grandes mudanças do cenário mundial no setor industrial advêm das empresas automobilísticas. Os novos modelos de gestão da produção desenvolvidos e aplicados nos mercados japoneses surgiram a partir de um conjunto de inovações que a Toyota, empresa do setor automobilístico, vinha aplicando e testando desde a metade do século passado.

Depois do sucesso obtido nas indústrias automobilísticas do Japão, a filosofia Lean chega ao ocidente e é amplamente divulgada e aplicada pelas indústrias. Seus resultados são percebidos e reconhecidos e a necessidade de tornar as empresas ocidentais mais competitivas levou-as a adotar as práticas do Lean como forma de melhorar seus indicadores de custos e qualidade, tornando-as mais produtivas com processos cada vez mais flexíveis (PANIZZOLO, 1998).

A base conceitual do modelo de gestão proposto pela Toyota originou as diretrizes gerais de um novo modelo de pensamento considerado enxuto. Esta nova forma de pensar orientada para o que realmente agrega valor aos olhos dos clientes vislumbra por onde passa este valor e, faz com que não haja paradas no processo, entregando somente o que for solicitado aos clientes com o máximo de eficácia e buscando sempre a melhoria do processo. Num processo de produção enxuta é preciso fazer mais, com cada vez menos: menos recursos, menos tempo, menos material, menos pessoas, menor espaço e exatamente o que o mercado deseja (WOMACK e JONES, 1998). A mudança de posição das máquinas e equipamentos aproximando as linhas de produção é necessária para obter um melhor desempenho e flexibilidade para todo o processo produtivo. Com esta prática, 
denominada de produção puxada, pode-se atender a demanda do mercado produzindo conforme o pedido do cliente e no momento que o cliente quer (SHANK, 2002).

Krafcik (1988) batizou este novo sistema de produção de Lean Production (Produção Enxuta), com o objetivo de fazer frente ao único modelo existente então conhecido como produção em massa. Para Ohno (1988), este novo modelo se originou da necessidade de sobrevivência do setor automobilístico de oferecer carros eficientes para um mercado pouco consumista comparado a outros países no final da segunda guerra mundial.

A proposta do Sistema Toyota de Produção é atingir o maior nível de produtividade, entregando ao mercado somente o necessário, no modelo solicitado e no tempo certo, eliminando assim os excessos de estoques intermediários e de produtos acabados. Para atender o principal objetivo de eliminar os desperdícios e reduzir os custos de produção, são desenvolvidas sub-metas, como: controle de qualidade, qualidade assegurada e valorização do ser humano, respeitando as condições de trabalhos (MONDEN, 1998).

\section{Vantagem competitiva}

Segundo Porter (1989) a definição de uma estratégia competitiva visa buscar um posicionamento competitivo favorável. Esta estratégia tem o objetivo de estabelecer uma posição lucrativa e sustentável contra as barreiras impostas pela concorrência. O autor argumenta que a estratégia de uma organização tem dois pontos fundamentais: A atratividade da indústria e os fatores que a determinam no longo prazo; e a posição competitiva relativa desta indústria. A primeira refere-se a capacidade de maximizar o retorno sobre seus investimentos no longo prazo e proporcionar vantagem competitiva sobre os concorrentes. A competitividade do mercado industrial propõe que para a empresa alcançar uma vantagem competitiva é necessário que ela posicione sua estratégia na busca de um dos dois tipos básicos de vantagem: liderança em custos ou diferenciação.

Adotar uma estratégia competitiva clara, objetiva e planejada, contribui para aumentar as chances de escolher a melhor estratégia para sua empresa. Uma organização ao longo da sua existência desenvolve uma cultura própria com seus valores aonde são alinhadas todas as estratégias. Por isso, conhecer o modelo a ser adotado é um passo muito importante para a escolha da estratégia adequada (DAVENPORT e PRUSAK, 1998).

Para considerar realmente que uma empresa está liderando seu mercado em custos, parte-se do princípio que exista um equilíbrio ou proximidade com base na diferenciação ligada aos seus produtos ou serviços, comparados com a dos seus concorrentes. Assim pode-se concluir que para se obter uma vantagem competitiva, é preciso que a organização apresente os requisitos que qualifiquem seus produtos semelhantes ao da concorrência e se diferencie nos fatores ganhadores de pedidos (SLACK, 1993). 
A soma das competências internas de uma organização através de seus recursos proporciona diferencial que se sobressaem no mercado. Estes diferenciais devem estar alinhados com as estratégias da empresa para atender aos critérios de vantagem competitiva. Essas competências são também conhecidas como capacidade estratégica e são classificadas em: capacidade que agregar valor, contribuindo para anular as ações da concorrência e impulsionar para as oportunidades; diferenciais raros que pouco ou nenhum concorrente possui; capacidades de inovação que sejam difíceis de serem imitadas pelo mercado e; por último, capacidades diferenciadas que não tenham equivalente na concorrência (HITT, IRELAND e HOSRISSON, 2002).

Para Porter (1989) a cadeia de valor de uma empresa é constituída por atividades primárias, relacionadas à competência essencial da empresa, e atividades de apoio, que suportam o desenvolvimento das primárias de forma que gerem vantagem competitiva para os clientes. A vantagem competitiva surge fundamentalmente do valor que uma empresa consegue criar aos seus clientes e que ultrapassa os custos de produção. Uma diferenciação sustentável exige que a empresa execute de uma forma única uma série de atividades de elevado valor acrescentado para o consumidor e que tenham forte influência no processo de compra

No ambiente interno empresarial são encontrados valores como habilidades, conhecimentos, recursos físicos gerenciais e tecnologias que são consideradas competências para gerar diferenciais competitivos para a empresa. Este diferencial garante vantagem frente ao mercado que muitas vezes é difícil de ser imitado (STOLLENWERK, 1999).

O desenvolvimento de um plano estratégico a fim de buscar competitividade, deve reforçar e motivar os pontos fortes da empresa. As competências elencadas por Stollenwerk (1999), quando identificadas nos pontos fortes que a empresa tem, servem para orientar para um novo posicionamento da estratégia competitiva (FLEURY E FLEURY, 2003).

Após elencados os principais conceitos e características relacionados à produção enxuta e ao processo de obtenção de vantagem competitiva, na seção seguinte é abordada a relação entre Lean Manufacturing e vantagem competitiva. A fundamentação desta relação é essencial para a consecução dos objetivos desta pesquisa.

\section{Relação entre lean manufacturing e vantagem competitiva}

O modelo proposto pela filosofia Lean contempla técnicas que garantem a vantagem competitiva para as indústrias que adotam esta prática. Vantagens como a confiabilidade de seus processos, qualidade nos produtos, velocidade de entrega, flexibilidade e redução dos custos, são alguns dos benefícios obtidos pelas empresas (SLACK, 1993).

Segundo Antunes (1995), o Lean Manufacturing caracteriza-se como um sistema de produção adaptável às flutuações de demanda, que proporciona alta qualidade e respostas rápidas. 
Sob a ótica da estratégia de produção, o Sistema Toyota de Produção ou Lean Manufacturing, surgiu originalmente para reduzir custos de fabricação, aumentar a flexibilidade das alterações no mix, introdução de novos produtos, tempo de resposta, melhorar a qualidade dos produtos e promover a inovação. Portanto, ele embarca todas essas qualificações e a necessidade constante de melhoria nas competências que sustentam a competitividade das empresas.

Para uma organização obter a vantagem competitiva, é necessário que desenvolva princípios alinhados com a gestão de manufatura enxuta seguindo as necessidades da produção e de projetos. Adotar princípios como, produção puxada, lotes de produção menores, redução dos estoques intermediários, nivelamento da produção e minimizar tempos de paradas, são considerados ações enxutas que elevam a vantagem competitiva sobre a concorrência (CUSUMANO, 1994).

Segundo Ritzman e Krajewski (2004), o Lean Manufacturign oferece ferramentas que contribuem significativamente para o desenvolvimento da vantagem competitiva. Ações voltadas para a qualidade do produto, inovação, produção puxada, redução de estoques permitem que apareçam as deficiências no processo e dessa forma sejam combatidas e eliminadas para atingir uma produção eficiente. Esta proposta está baseada na implantação do processo de melhoria contínua e tem como premissa o alcance das metas definidas no planejamento.

Segundo Skinner (1969), as decisões voltadas para o chão de fábrica devem ser planejadas e desenvolvidas no momento da construção das estratégias competitivas da organização, e devem estar ligadas ao mapa estratégico de toda a organização a fim de aumentar as ações competitivas.

Pela necessidade de as decisões de uma empresa estar ligadas ao mapa estratégico de toda a organização, nesta pesquisa adotaram-se os princípios do Balanced Scorecard (BSC) como indicadores para a avaliação do processo de obtenção de vantagem competitiva. O conceito e as características desta ferramenta são tecidos no item seguinte.

\section{Fundamentos do balanced scorecard}

O BSC é um método utilizado por muitas organizações para orientar os líderes das suas empresas a fim de desenvolver uma estratégia desde o início até o fim, fazendo com que cada colaborador da organização esteja comprometido com a sua implementação (KAPLAN e NORTON, 2000).

Segundo Epstein e Manzoni (1998), a proposta de Kaplan e Norton em 1992 quando foi desenvolvido o Balanced Scorecard (BSC), tinha o objetivo de absorver e interpretar toda a complexidade de desempenho da organização. A partir daí começou a ser utilizada por empresas de todo o mundo.

Quando uma empresa decide implementar um sistema que permite medir e avaliar seu desempenho e eficiência organizacional, corre alguns riscos de obter valores distorcidos e 
incompatíveis com o modelo adotado. Por isso, as diferentes situações que o mercado apresenta assim como o segmento em que a empresa atua, estratégias de desenvolvimento de produtos pressupõem diferentes Scorecards (KAPLAN e NORTON, 1993).

Segundo Kaplan e Norton (1996) à ausência de uma definição clara de objetivos para uma estratégia comum e sua transição no ambiente interno da organização poderá refletir no sucesso do modelo adotado. $\mathrm{O}$ fato de as pessoas conhecerem os objetivos e metas estabelecidas pela corporação não é suficiente para mudar a atitude dos funcionários. Faz-se necessário criar uma aliança entre os objetivos e medidas estabelecidos e integrar com os indivíduos, alinhando com as metas de longo prazo na organização.

Em cada método (comparativo) em uma grande amostragem refletirá em objetivos pontuais. Algumas empresas cometem alguns erros ao considerar o BSC puramente como um projeto isolado para criar métricas, ao invés de um grande projeto responsável por mudanças estratégicas que contemplam detalhes minuciosos da empresa (KAPLAN e NORTON, 1999).

Para traduzir a estratégia da empresa são utilizados os indicadores (aprendizado e crescimento, processos internos, clientes e financeiro) que devem ser trabalhadas no sentido de auxiliar qualquer um na organização a tentar alcançar as prioridades estratégicas. Assim as empresas serão capazes de não apenas criar estratégia, mas também colocá-las em prática (KAPLAN e NORTON, 2000).

\section{Análise geral dos resultados da pesquisa com a empresa Rudnick}

A seguir são apresentados dois quadros resumo: um contendo o resultado das entrevistas realizadas com a direção da empresa (visão estratégica); e o outro contendo o resultado das entrevistas realizadas com os funcionários da empresa Rudnick (visão operacional).

\subsection{Visão estratégica}

A seguir são apresentados os resultados das entrevistas realizadas com a direção da empresa Rudnick (visão estratégica). 
Quadro1 - Resumo das perspectivas na visão estratégica da empresa Rudnick

\begin{tabular}{|c|c|c|c|}
\hline $\begin{array}{c}\text { Perspectiva } \\
\text { Aprendizado /Crescimento }\end{array}$ & $\begin{array}{c}\text { Perspectiva } \\
\text { Processos Internos }\end{array}$ & $\begin{array}{l}\text { Perspectiva } \\
\text { Cliente }\end{array}$ & $\begin{array}{l}\text { Perspectiva } \\
\text { Financeira }\end{array}$ \\
\hline $\begin{array}{c}\text { - Consultoria por } 2 \text { anos; } \\
\text { - Cliente dos EUA sugeriu o Lean; } \\
\text { - Os gestores fizeram pós-graduação em } \\
\text { Lean; } \\
\text { - Cada área tem um grupo melhoria; } \\
\text { - Comitê Lean; } \\
\text { - Treinamentos, bolsa de estudo, } \\
\text { reuniões, visitas; } \\
\text { - Treinamento especifico, } 120 \text { pessoas } \\
\text { por } 4 \text { meses; } \\
\text { - Treinamento com 100\% dos } \\
\text { funcionários; } \\
\text { - Meta } 32 \mathrm{~h} \text { h/a; } \\
\text { - Café para comemorar resultados. }\end{array}$ & $\begin{array}{c}\text { - Mapa fluxo valor; } \\
\text { - Redução lead time (15-8; } \\
\text { 12-8; 23-7); } \\
\text { - Eliminou setor de revisão } \\
\text { (layout); } \\
\text { - Reduziu estoque, } \\
\text { transportes, movimentos, } \\
\text { pessoas, produção excesso, } \\
\text { refugo e retrabalho; } \\
\text { - Qualidade na fonte; } \\
\text { - Gestão a vista; } \\
\text { - Aumento produtividade. }\end{array}$ & $\begin{array}{l}\text { - Atendimento } \\
\text { integral; } \\
\text { - Atendimentos } \\
\text { prazo; } \\
\text { - Melhor } \\
\text { comunicação com } \\
\text { clientes e } \\
\text { fornecedores; } \\
\text { - Redução índice } \\
\text { de reclamação. }\end{array}$ & $\begin{array}{l}\text { - Metas atingidas } \\
\text { - Aumento de } \\
\text { produtividade. } \\
\text { - Redução de } 1200 \\
\text { p/ } 800 \text { funcionários; } \\
\text { - Aumento de } \\
\text { competitividade } \\
\text { - Ótimos resultados } \\
\text { financeiros. }\end{array}$ \\
\hline
\end{tabular}

Fonte: Pesquisa de campo (2011)

\subsection{Visão operacional}

A seguir são apresentados os resultados das entrevistas realizadas com os funcionários da empresa Rudnick (visão operacional).

Quadro2 - Resumo das perspectivas na visão operacional da empresa Rudnick

\begin{tabular}{|c|c|c|c|}
\hline $\begin{array}{l}\text { Perspectiva } \\
\text { Aprendizado } \\
\text { /Crescimento }\end{array}$ & $\begin{array}{c}\text { Perspectiva } \\
\text { Processos Internos }\end{array}$ & $\begin{array}{l}\text { Perspectiva } \\
\text { Cliente }\end{array}$ & $\begin{array}{c}\text { Perspectiva } \\
\text { Financeira }\end{array}$ \\
\hline $\begin{array}{l}\text { - Comunicação por toda } \\
\text { empresa pelos gestores; } \\
\text { - Reuniões de apresentação } \\
\text { dos indicadores; } \\
\text { - Participam grupos de } \\
\text { melhorias e comitês; } \\
\text { - Treinamentos, visitas e } \\
\text { pós-graduação; } \\
\text { - Participam da implantação } \\
\text { das ferramentas lean. }\end{array}$ & $\begin{array}{l}\text { - Lotes menores; } \\
\text { - Qualidade na fonte; } \\
\text { - Poka yoke; } \\
\text { - Melhoria layout; } \\
\text { - Fluxo contínuo; } \\
\text { - Conceito célula; } \\
\text { - Gestão á vista; } \\
\text { - Redução lead time; } \\
\text { - Melhoria comunicação. }\end{array}$ & $\begin{array}{l}\text { - Desenvolvimento de } \\
\text { novos produtos; } \\
\text { - Satisfação do cliente; } \\
\text { - Flexibilidade; } \\
\text { - Redução de devolução e } \\
\text { reclamação; } \\
\text { - Melhora imagem da } \\
\text { empresa. }\end{array}$ & $\begin{array}{l}\text { - Toda melhoria nos } \\
\text { processos resulta em } \\
\text { melhor desempenho } \\
\text { financeiro; } \\
\text { - Sem o lean a empresa } \\
\text { teria sofrido muito a crise. }\end{array}$ \\
\hline
\end{tabular}

Fonte: Pesquisa de campo (2011)

\section{Análise geral dos resultados da pesquisa com a empresa Artefama}

\subsection{Visão estratégica}

A seguir são apresentados os resultados das entrevistas realizadas com a direção da empresa Artefama (visão estratégica). 
Quadro 3 - Análise das perspectivas na visão estratégica da empresa Artefama

\begin{tabular}{|c|c|c|c|}
\hline $\begin{array}{c}\text { Perspectiva } \\
\text { Aprendizado /Crescimento }\end{array}$ & $\begin{array}{c}\text { Perspectiva } \\
\text { Processos Internos }\end{array}$ & $\begin{array}{l}\text { Perspectiva } \\
\text { Cliente }\end{array}$ & $\begin{array}{l}\text { Perspectiva } \\
\text { Financeira }\end{array}$ \\
\hline $\begin{array}{c}\text { - O diretor teve a iniciativa do Lean; } \\
\text { - Consultoria externa 1ano; } \\
\text { - Foco nas pessoas; } \\
\text { - Resultados pelas pessoas; } \\
\text { - Treinamento e capacitação de } \\
\text { colaboradores; } \\
\text { - Visitas de benchmarking por pessoas } \\
\text { de todas áreas; } \\
\text { - Todos os gestores fizeram a pós } \\
\text { graduação; } \\
\text { - 50 pessoas fizeram a pós; } \\
\text { - Coordenação Lean + } 3 \text { pessoas; } \\
\text { - Direção apóia o Lean e reconhece a } \\
\text { importância dos treinamentos; } \\
\text { - Conforme necessidade chama nova } \\
\text { consultoria; } \\
\text { - Grupos de melhorias fazem reunião } \\
\text { mensal. }\end{array}$ & $\begin{array}{c}\text { - Pouco investimento e } \\
\text { muitas melhorias; } \\
\text { - Venda equipamento } \\
\text { descartado e retorno } \\
\text { para melhorias; } \\
\text { - Implantado o 5S, } \\
\text { Kaizen / SMED; } \\
\text { - 2009 implantado o } \\
\text { MFV } \\
\text { - 20\% espaço liberado; } \\
\text { - Redução do } \\
\text { refugo/retrabalho; } \\
\text { - Reunião semanal para } \\
\text { apresentar indicadores; } \\
\text { - Gestão à vista; } \\
\text { - Melhor comunicação. }\end{array}$ & $\begin{array}{l}\text { - Redução de índice } \\
\text { reclamação; } \\
\text { - Redução de índice } \\
\text { devolução; } \\
\text { - Confiabilidade dos } \\
\text { produtos e } \\
\text { qualidade; } \\
\text { - Redução de 50\% } \\
\text { lead time (14 p 6); } \\
\text { - Melhorou a } \\
\text { imagem empresa se } \\
\text { tornando referência } \\
\text { em Lean; } \\
\text { - Redução de } \\
\text { ocorrências de } \\
\text { assistência técnica. }\end{array}$ & $\begin{array}{l}\text { - Redução de desperdício; } \\
\text { - Aumento de } \\
\text { produtividade; } \\
\text { - Impacto direto no lucro; } \\
\text { - Ampliou a carteira de } \\
\text { clientes; } \\
\text { - Desenvolveu novos } \\
\text { produtos; } \\
\text { - Redução de estoque em } \\
\text { processo e de produto } \\
\text { acabado; } \\
\text { - Redução nos custos. }\end{array}$ \\
\hline
\end{tabular}

Fonte: Pesquisa de campo (2011)

\subsection{Visão operacional}

A seguir são apresentados os resultados das entrevistas realizadas com os funcionários da empresa Artefama (visão operacional).

Quadro 4 - Análise das perspectivas na visão operacional da empresa Artefama

\begin{tabular}{|c|c|c|c|}
\hline $\begin{array}{l}\text { Perspectiva } \\
\text { Aprendizado } \\
\text { /Crescimento }\end{array}$ & $\begin{array}{c}\text { Perspectiva } \\
\text { Processos Internos }\end{array}$ & $\begin{array}{l}\text { Perspectiva } \\
\text { Cliente }\end{array}$ & $\begin{array}{l}\text { Perspectiva } \\
\text { Financeira }\end{array}$ \\
\hline $\begin{array}{c}\text { - Treinamento nas } \\
\text { ferramentas Lean; } \\
\text { - Implantação em maio } \\
\text { 2007; } \\
\text { - Pós-graduação em Lean } \\
\text { - Participação em. projetos, } \\
\text { implantação das } \\
\text { ferramentas, como } \\
\text { multiplicador; } \\
\text { - Dar idéias, sugestões de } \\
\text { melhorias, participação em } \\
\text { grupos melhorias; } \\
\text { - Visitas em empresas } \\
\text { Whirlpool, Embraco, } \\
\text { Docol, Volvo... }\end{array}$ & $\begin{array}{c}\text { - Processos mais simples; } \\
\text { - Autonomação; } \\
\text { - Implantação poka yoke; } \\
\text { - Gestão a vista; } \\
\text { - Processo padronizado; } \\
\text { - Trabalho padrão; } \\
\text { - Redução variabilidade; } \\
\text { - Aumento de desempenho do } \\
\text { processo; } \\
\text { - Aumento da capacidade e } \\
\text { confiabilidade; } \\
\text { - Técnicas de resolução de problemas; } \\
\text { - Técnicas para eliminar desperdícios; } \\
\text { - Qualidade na fonte, fluxo contínuo, } \\
\text { redução de refugo, células de } \\
\text { manufatura, TPM, SMED, } \\
\text { manutenção autônoma; } \\
\text { - Fluxo de informação direta (cadeia } \\
\text { de ajuda). }\end{array}$ & $\begin{array}{c}\text { - Novos pedidos; } \\
\text { - Novos produtos; } \\
\text { - Redução de solicitação } \\
\text { reposição; } \\
\text { - Pesquisa satisfação; } \\
\text { - Melhoria da qualidade } \\
\text { do produto; } \\
\text { - Redução lead time; } \\
\text { - Elogios do cliente para } \\
\text { o comercial; } \\
\text { - Melhora imagem da } \\
\text { empresa; } \\
\text { - Solicitação de visitas } \\
\text { por várias empresas. }\end{array}$ & $\begin{array}{l}\text { - Redução custos com } \\
\text { eliminação dos } \\
\text { desperdícios; } \\
\text { - Redução de mão de } \\
\text { obra; } \\
\text { - Redução retrabalho } \\
\text { e refugo; } \\
\text { - Redução custo de } \\
\text { manutenção; } \\
\text { - Aumento da } \\
\text { disponibilidade das } \\
\text { máquinas e equipes; } \\
\text { - Produzindo mais } \\
\text { com menos; } \\
\text { - Aumento da } \\
\text { produtividade. }\end{array}$ \\
\hline
\end{tabular}

Fonte: Pesquisa de campo (2011) 


\section{Semelhanças entre os casos}

As duas empresas pesquisadas apresentaram ao longo da implantação do Lean Manufacturing ações semelhantes. Abaixo são apresentadas as semelhanças que as empresas Artefama e Rudnick tiveram sob a visão da Direção (visão estratégica) e também sob a ótica operacional (visão operacional), respeitando sempre as quatro perspectivas do BSC.

\subsection{Visão estratégica}

Quadro 1 - Relação das semelhanças na visão estratégica sob as perspectivas do BSC

\begin{tabular}{|c|c|c|c|}
\hline Aprend./Crescim. & Processos & Clientes & Financeira \\
\hline Consultoria & Mapa fluxo valor & $\begin{array}{l}\text { Redução índice } \\
\text { reclamação }\end{array}$ & Redução desperdício \\
\hline Pós para gestores & Qualidade fonte & $\begin{array}{c}\text { Melhor imagem da } \\
\text { empresa }\end{array}$ & Aumento produtividade \\
\hline Grupos melhorias & Gestão à vista & Redução lead time & Redução custos \\
\hline $\begin{array}{l}\text { Treinamentos } \\
\text { funcionários }\end{array}$ & $\begin{array}{c}\text { Redução refugo e } \\
\text { retrabalho }\end{array}$ & & \\
\hline Comitê lean & $\begin{array}{c}\text { Implantação ferramentas } \\
\text { lean }\end{array}$ & & \\
\hline $\begin{array}{c}\text { Reunião mensal e } \\
\text { semanal }\end{array}$ & Aumento produtividade & & \\
\hline \multicolumn{4}{|l|}{ Bolsa de estudos } \\
\hline Visitas & & & \\
\hline
\end{tabular}

Fonte: Pesquisa de campo (2011)

\subsection{Visão operacional}

Quadro 6: Relação das semelhanças na visão operacional sob as perspectivas do BSC

\begin{tabular}{|c|c|c|c|}
\hline Aprend./Crescim. & Processos & Clientes & Financeira \\
\hline Treinamento & $\begin{array}{c}\text { Implantação } \\
\text { ferramentas lean }\end{array}$ & $\begin{array}{c}\text { Desenvolvimento de } \\
\text { novos produtos }\end{array}$ & $\begin{array}{c}\text { Todas as melhorias resultaram em } \\
\text { um retorno financeiro positivo }\end{array}$ \\
\hline Grupo melhorias & & Satisfação cliente & \\
\hline Visitas & & $\begin{array}{c}\text { Melhor imagem da } \\
\text { empresa }\end{array}$ & \\
\hline Reuniões & & & \\
\hline
\end{tabular}

Fonte: Pesquisa de campo (2011)

\section{Impactos do lean manufacturing na obtenção de vantagem competitiva}

A análise dos impactos do Lean Manufacturing na obtenção de vantagem competitiva está alicerçada na triangulação entre as informações referentes aos critérios de obtenção de vantagem competitiva descritos na fundamentação teórica por Slack (1993), a análise geral dos resultados da pesquisa com a empresa Artefama e a análise geral dos resultados da pesquisa com a empresa Rudnick. 
Partindo desta triangulação, a análise dos impactos do Lean para obtenção de vantagem competitiva foi realizada da seguinte maneira: primeiramente foram determinados os critérios de obtenção de vantagem competitiva descritos por Slack (1993); em seguida, foram listadas as principais semelhanças existentes entre cada uma das empresas relacionadas a cada um dos indicadores do BSC, em nível estratégico e operacional.

A partir disso, estruturou-se um quadro de análise contendo os critérios de vantagem competitiva e as principais semelhanças entre as empresas, para cada uma das perspectivas do BSC. Neste quadro são assinaladas em que vantagem competitiva, segundo os critérios de Slack (1993) cada semelhança está inserida. E, por fim, são realizadas as análises dos resultados. É válido ressaltar, que se optou pelas semelhanças para a realização da análise das contribuições do Lean por uma questão de delimitação da pesquisa.

\subsection{Nível estratégico}

Quadro 7 - Relação das semelhanças com os critérios de Slack (1993) na visão estratégica sob a perspectiva de aprendizado e crescimento

\begin{tabular}{|c|c|c|c|c|c|}
\hline \multicolumn{7}{|c|}{ CRITÉRIOS DE SLACK (1993) } \\
\hline Semelhanças & Qualidade & Velocidade & Confiabilidade & Flexibilidade & Custos \\
\hline Consultoria & & $\mathrm{X}$ & $\mathrm{X}$ & & \\
\hline Pós para gestores & $\mathrm{X}$ & & & & \\
\hline Grupos melhorias & $\mathrm{X}$ & & & & \\
\hline $\begin{array}{c}\text { Treinamentos } \\
\text { funcionários }\end{array}$ & $\mathrm{X}$ & & & $\mathrm{X}$ & \\
\hline Comitê lean & $\mathrm{X}$ & $\mathrm{X}$ & $\mathrm{X}$ & \\
\hline $\begin{array}{c}\text { Reunião mensal e } \\
\text { semanal }\end{array}$ & $\mathrm{X}$ & & & & \\
\hline Bolsa de estudos & $\mathrm{X}$ & & & & \\
\hline Visitas & $\mathrm{X}$ & & & & \\
\hline
\end{tabular}

Fonte: Pesquisa de campo (2011)

Cada uma das semelhanças do quadro 7 está relacionada com os critérios de Slack (1993). A relação do item consultoria com os critérios velocidade e confiabilidade foi destacada a partir da afirmação da Direção das duas empresas. Em virtude da necessidade de ambas empresas obterem resultados positivos num curto espaço de tempo, dando mais velocidade as ações, optou-se pela contratação de consultoria externa nessas empresas. Isso daria credibilidade e confiança ao processo. Segundo Slack (1993), os critérios de velocidade e confiabilidade caminham juntos, pois, quando a empresa consegue entregar os pedidos feitos pelo cliente dentro do prazo isso gera mais confiança por parte do mercado.

Slack (1993) afirma que o indivíduo influencia a qualidade e tem a responsabilidade de determinar suas próprias exigências em relação ao conceito de qualidade. $\mathrm{O}$ autor afirma ainda que a qualidade está focada no indivíduo e não na técnica ou filosofia, pois, pessoas que não cometem erros, melhoram a qualidade do seu serviço e aprendem com suas experiências. Portanto, as 
semelhanças de pós-graduação, grupos de melhorias, comitês, reuniões, treinamentos, visitas e bolsa de estudos destacadas nas duas empresas estão relacionados ao critério qualidade. Os diretores da Rudnick e Artefama, afirmam que a qualidade vem das pessoas e quanto mais preparadas e treinadas elas estiverem, melhores serão seus trabalhos. Para a Direção das empresas pesquisadas, o comitê lean é estratégico e possibilita a visão de todo o negócio. Dessa forma, a visão dos diretores está relacionado com todos os critérios definidos por Slack (1993), pois, é este comitê que alinha todas as ações do lean com os indicadores estratégicos da organização.

Quadro 8 - Relação das semelhanças com os critérios de Slack (1993) na visão estratégica sob a perspectiva de processos

\begin{tabular}{|l|c|c|c|c|c|}
\hline \multicolumn{7}{|c|}{ CRITÉRIOS DE SLACK (1993) } \\
\hline Semelhanças & Qualidade & Velocidade & Confiabilidade & Flexibilidade & Custos \\
\hline Mapa fluxo valor & & $\mathrm{X}$ & $\mathrm{X}$ & $\mathrm{X}$ & $\mathrm{X}$ \\
\hline Qualidade fonte & $\mathrm{X}$ & $\mathrm{X}$ & $\mathrm{X}$ & $\mathrm{X}$ \\
\hline Gestão à vista & & $\mathrm{X}$ & & $\mathrm{X}$ & $\mathrm{X}$ \\
\hline $\begin{array}{l}\text { Redução refugo e } \\
\text { retrabalho }\end{array}$ & & $\mathrm{X}$ & $\mathrm{X}$ & $\mathrm{X}$ & \\
\hline $\begin{array}{l}\text { Implantação } \\
\text { ferramentas lean }\end{array}$ & $\mathrm{X}$ & $\mathrm{X}$ & $\mathrm{X}$ & \\
\hline Aumento produtividade & & \multicolumn{2}{|c|}{} \\
\hline
\end{tabular}

Fonte: Pesquisa de campo (2011)

O mapa do fluxo de valor está relacionado aos critérios de velocidade e confiabilidade, pois, segundo Slack (1993), estes critérios caminham juntos. A partir do momento que a organização tem velocidade no processo o cliente recebe dentro do prazo. Segundo a Direção das empresas estudadas, o mapa indica o cenário e a situação da fábrica, auxiliando dessa forma, as ações a serem tomadas. Uma vez que se sabe onde deve atuar, os resultados serão mais rápidos e a confiança por parte dos envolvidos aumenta, afirmam os diretores entrevistados.

As semelhanças de qualidade na fonte e implantação das ferramentas lean, devido a sua abrangência têm impacto direto em todos os indicadores e critérios definidos por (SLACK, 1993). Conforme a Direção da Rudnick e da Artefama, a qualidade na fonte e as ferramentas lean contribuíram para um melhor desempenho no processo, reduzindo custos, aumentando a velocidade, flexibilidade e a confiabilidade. A implantação do conceito de gestão à vista ajudou na obtenção de uma maior velocidade nas decisões e ações a serem tomadas. O aumento de produtividade, conforme depoimento da Direção nas entrevistas feita neste estudo, auxiliou as empresas a tornarem os processos mais confiáveis, rápidos e mais flexíveis. A redução do refugo e do retrabalho tem impacto em todos os critérios definido por Slack (1993), porém, a Direção das empresas fez questão de ressaltar que os resultados são diretamente relacionados a redução dos custos. 
Quadro 9 - Relação das semelhanças com os critérios de Slack (1993) na visão estratégica sob a perspectiva do cliente

\begin{tabular}{|c|c|c|c|c|c|}
\hline \multicolumn{5}{|c|}{ CRITÉRIOS DE SLACK (1993) } \\
\hline Semelhanças & Qualidade & Velocidade & Confiabilidade & Flexibilidade & Custos \\
\hline $\begin{array}{c}\text { Redução índice } \\
\text { reclamação }\end{array}$ & & $X$ & & \\
\hline $\begin{array}{c}\text { Melhor imagem da } \\
\text { empresa }\end{array}$ & & $X$ & & \\
\hline Redução lead time & & $X$ & $X$ & & \\
\hline
\end{tabular}

Fonte: Pesquisa de campo (2011)

Segundo Slack (1993), o cliente percebe a velocidade de uma operação pelo tempo entre o momento que ele faz o pedido até o momento de recebê-lo. Mais do que dinheiro, tempo é valor, pois além de agregar valor para o processo ele também beneficia o cliente que não precisa esperar além do prazo definido. As semelhanças de redução no índice de reclamação e melhor imagem da empresa se relacionam diretamente com os critérios de confiabilidade, pois, segundo a Direção das empresas o cliente reconheceu o melhor atendimento elogiando as ações internas e valorizando mais a imagem da empresa. Com a redução do lead time, aumentou a velocidade no processo e melhorou a confiança por parte do cliente com a empresa. Para a empresa conquistar a confiabilidade do mercado, ela precisa atender aos pedidos do cliente de forma integral e no prazo, além de honrar os compromissos assumidos com ele e garantir que o cliente seja atendido na sua necessidade (SLACK, 1993).

Quadro 10 - Relação das semelhanças com os critérios de Slack (1993) na visão estratégica sob a perspectiva financeira

\begin{tabular}{|c|c|c|c|c|c|}
\hline \multicolumn{7}{|c|}{ CRITÉRIOS DE SLACK (1993) } \\
\hline Semelhanças & Qualidade & Velocidade & Confiabilidade & Flexibilidade & Custos \\
\hline Redução desperdício & & & & & $X$ \\
\hline Aumento produtividade & & $X$ & $X$ & $X$ & $X$ \\
\hline Redução custos & & & & & \\
\hline
\end{tabular}

Fonte: Pesquisa de campo (2011)

A manufatura tem responsabilidade direta pela redução dos custos. A consciência organizacional reconhece que a produção tem influência na redução dos custos operacionais (SLACK, 1993). Conforme a Direção das empresas, todas as ações para eliminar os desperdícios resultam diretamente em redução de custos. Por esse motivo a semelhança redução de desperdício está alinhada aos custos. A implantação das ferramentas lean, como células de manufatura, manutenção preventiva total, $5 \mathrm{~S}$, dispositivos a prova de falhas, mapa de fluxo de valor, fluxo contínuo, entre outras, fizeram com que houvesse um aumento na produtividade e assim a empresa se posicionou de forma mais agressiva, conquistando vantagem competitiva no mercado. Segundo a Direção, esse aumento de produtividade gera maior velocidade no processo, com mais confiabilidade e flexibilidade. 
Segundo Slack (1993), o custo está no centro das metas e diretrizes da manufatura, como um indicador que tem o maior impacto sobre os resultados financeiros. A Direção das empresas pesquisadas concorda em dizer que as ações implantadas como redução de estoque, redução de refugo, dos desperdícios, teve impacto na redução dos custos e como consequência melhor resultado financeiro.

\subsection{Nível operacional}

Quadro 11 - Relação das semelhanças com os critérios de Slack (1993) na visão operacional sob a perspectiva de crescimento e aprendizado

\begin{tabular}{|c|c|c|c|c|c|}
\hline \multicolumn{7}{|c|}{ CRITÉRIOS DE SLACK (1993) } \\
\hline Semelhanças & Qualidade & Velocidade & Confiabilidade & Flexibilidade & Custos \\
\hline Treinamento & $\mathrm{X}$ & & & & \\
\hline Grupo melhorias & $\mathrm{X}$ & & & & \\
\hline Visitas & $\mathrm{X}$ & & & & \\
\hline Reuniões & $\mathrm{X}$ & & & & \\
\hline
\end{tabular}

Fonte: Pesquisa de campo (2011)

$\mathrm{Na}$ perspectiva de aprendizado e crescimento, sob a visão operacional apresenta-se as seguintes semelhanças: treinamento, grupo de melhorias, visitas e reuniões. Estas semelhanças estão relacionadas com o critério de vantagem competitiva de qualidade definido por Slack (1993). Segundo o autor o indivíduo influencia a qualidade e determina seu próprio conceito de qualidade. Slack (1993) diz ainda que a qualidade está focada no indivíduo e não na técnica ou filosofia, pois, pessoas que não cometem erros, melhoram a qualidade do seu serviço e aprendem com suas experiências, são indivíduos que têm mais qualidade.

Quadro 122 - Relação das semelhanças com os critérios de Slack (1993) na visão operacional sob a perspectiva de processos

\begin{tabular}{|c|c|c|c|c|c|}
\hline \multicolumn{7}{|c|}{ CRITÉRIOS DE SLACK (1993) } \\
\hline Semelhanças & Qualidade & Velocidade & Confiabilidade & Flexibilidade & Custos \\
\hline $\begin{array}{c}\text { Implantação } \\
\text { ferramentas lean }\end{array}$ & $\mathrm{X}$ & $\mathrm{X}$ & $\mathrm{X}$ & $\mathrm{X}$ & $\mathrm{X}$ \\
\hline
\end{tabular}

Fonte: Pesquisa de campo (2011)

Com a implantação das ferramentas lean, todo o processo é beneficiado, pois, a abrangência das melhorias afeta toda a manufatura. Ferramentas como células de manufatura, fluxo contínuo, nivelamento de produção, balanceamento da produção são algumas técnicas que contribuem para dar maior velocidade no processo gerando mais confiança e flexibilidade na cadeia produtiva. Outras ferramentas como, $5 \mathrm{~S}$, dispositivo a prova de falhas, qualidade na fonte, kaizen, mapa de fluxo de valor contribuem para elevar o nível da qualidade, reduzindo os retrabalhos e refugos impactando na redução dos custos de produção. 
Segundo depoimento dos funcionários referente às ferramentas lean, todos concordam que as melhorias foram percebidas em aspectos como: melhoria da qualidade, melhor fluxo de produção, troca rápida de ferramentas, enfim, colaborando para que a empresa seja competitiva com processos mais enxutos. Para ilustrar o exposto, segue uma frase de um dos funcionários que responderam ao questionário, quando perguntado se o lean contribui para melhorar a produção e atingir as metas: "Sim, com ferramentas como andon, trabalho padrão, kanban de movimentação, Team Leader, GBO, cadeia de ajuda, gestão visual, 5S se tem controle de processo durante todo o tempo... Facilita o atingimento das metas".

Quadro 13 - Relação das semelhanças com os critérios de Slack (1993) na visão operacional sob a perspectiva de clientes

\begin{tabular}{|c|c|c|c|c|c|}
\hline \multicolumn{7}{|c|}{ CRITÉRIOS DE SLACK (1993) } \\
\hline Semelhanças & Qualidade & Velocidade & Confiabilidade & Flexibilidade & Custos \\
\hline $\begin{array}{c}\text { Desenvolvimento de } \\
\text { novos produtos }\end{array}$ & & & & $X$ & \\
\hline Satisfação cliente & & $\mathrm{X}$ & $\mathrm{X}$ & & \\
\hline $\begin{array}{c}\text { Melhor imagem da } \\
\text { empresa }\end{array}$ & & $\mathrm{X}$ & & \\
\hline
\end{tabular}

Fonte: Pesquisa de campo (2011)

As semelhanças sob a perspectiva do cliente são: desenvolvimento de novos produtos, satisfação do cliente e melhor imagem da empresa. Estas semelhanças estão relacionadas com os critérios definidos por Slack (1993) no quadro 13. Na semelhança de desenvolvimento de novos produtos a relação é feita com o critério de flexibilidade. Segundo as respostas dos funcionários, os respondentes sinalizaram que a redução do lead time e o aumento da produtividade geraram mais flexibilidade no processo e isso foi causado pelas melhorias implantadas pelos grupos de melhoria. Estes são considerados os grandes responsáveis pelo desenvolvimento de novos produtos e maior flexibilidade nos processos produtivos.

Estes foram considerados, também, os principais fatores que contribuíram para o aumento na satisfação dos clientes, além de serem percebidos nos indicadores de redução no índice de reclamação, das devoluções assim como melhora na percepção da imagem da empresa.

Quadro 14 - Relação das semelhanças com os critérios de Slack (1993) na visão operacional sob a perspectiva financeira

\begin{tabular}{|c|c|c|c|c|c|}
\hline \multicolumn{7}{|c|}{ CRITÉRIOS DE SLACK (1993) } \\
\hline Semelhanças & Qualidade & Velocidade & Confiabilidade & Flexibilidade & Custos \\
\hline $\begin{array}{c}\text { Todas as melhorias } \\
\text { resultaram em um } \\
\text { retorno financeiro } \\
\text { positivo }\end{array}$ & & & & & \\
\end{tabular}

Fonte: Pesquisa de campo (2011)

$\mathrm{Na}$ perspectiva financeira, o resultado obtido com a resposta do questionário na visão operacional das duas empresas teve uma semelhança comum. A implantação das mais variadas ferramentas do lean e as diversas ações de melhorias contínuas resultaram em reduções de 
desperdícios, de tempo, redução de refugo e retrabalho, entre outras. Conforme os respondentes, os impactos de todas estas ações de melhorias tiveram como maior foco a redução de custos, portanto conforme os critérios definidos por Slack (1993) foi relacionado à semelhança entre as empresas pesquisadas com o critério de custos.

É válido ressaltar, que se optou pelas semelhanças para a realização da análise dos impactos do Lean por uma questão de delimitação da pesquisa. Considera-se que os fatores que se repetem têm uma relevância maior dentro de cada perspectiva estudada no processo Lean.

Os resultados relacionados aos impactos do Lean na obtenção de vantagem competitiva são apresentados a seguir nas considerações finais.

\section{Considerações finais}

O objetivo principal desta pesquisa é analisar a contribuição do Lean Manufacturing para a obtenção da vantagem competitiva nas empresas do setor moveleiro pesquisadas na região de São Bento do Sul - Artefama e Rudnick.

Inicialmente, para atender o objetivo principal da pesquisa, foi realizada uma revisão bibliográfica que possibilita contextualizar o lean manufacturing a fim de socializar seus conceitos e sua proposta para as organizações alcançarem a competitividade. Num processo de produção enxuta é preciso fazer mais, com cada vez menos: menos recursos, menos tempo, menos material, menos pessoas, menor espaço e exatamente o que o mercado deseja (WOMACK; JONES, 1998). Neste sentido foram desenvolvidos no capítulo 2 os seguintes temas: conceitos do lean manufacturing, princípios do lean manufacturing, os sete desperdícios e produção enxuta e suas ferramentas.

Para contribuir com a filosofia lean e analisar o processo de vantagem competitiva nas organizações, foi conceituado no item 2.3 outro tema relevante para esta pesquisa que trata do processo de obtenção de vantagem competitiva. Procurou-se abordar o tema de forma objetiva sob a perspectiva de vários autores, como: Porter (1989); Slack (1993); Davenport e Prusak (1998); Teixeira Filho (2000), entre outros. Segundo Porter (1989) a definição de uma estratégia competitiva visa buscar um posicionamento competitivo favorável para a organização diante da concorrência.

Para a consecução do objetivo deste trabalho foi apresentado também uma relação entre o tema lean manufacturing e o conceito de vantagem competitiva. Portanto, no item 2.4 busca-se alinhar as propostas oferecidas com a implantação do lean com o conceito da obtenção da vantagem competitiva. Esta relação entre o lean e a vantagem competitiva fica mais evidente quando Ritzman e Krajewski (2004) afirmam que o Lean Manufacturing oferece ferramentas que contribuem significativamente para o desenvolvimento da vantagem competitiva. 
Dois modelos de questionários foram desenvolvidos com a finalidade de analisar como o sistema Lean Manufactoring foi implementado nas organizações estudadas; e também, a fim de coletar as informações referentes à implantação e obtenção dos resultados com o lean. $\mathrm{O}$ formato do questionário estratégico contempla perguntas mais aprofundadas, pois, foi direcionado para a Direção das duas empresas pesquisadas. Isto foi feito porque se considera que os diretores possuem informações relevantes sobre todas as áreas. O questionário aplicado aos funcionários foi realizado procurando atender a limitação de informações que os colaboradores das empresas pesquisadas possuem em relação ao Lean manufacturing. Os questionários contemplam os conceitos do Balanced ScoreCard sob suas quatro perspectivas: de aprendizado e crescimento, perspectiva de processo, perspectiva de cliente e perspectiva financeira. Neste contexto, buscou-se obter as informações pertinentes a implementação da filosofia lean, assim como, obter informações a cerca dos resultados obtidos com este modelo de gestão adotado pelas empresas.

Procurou-se ainda, identificar e delimitar as semelhanças encontradas na pesquisa realizada nas duas empresas relacionadas aos procedimentos de lean manufacturing. Para isso, no item 4.4 são apresentadas as semelhanças encontradas sob a ótica da Direção das duas empresas, elencadas num quadro e organizadas separadamente em cada uma das perspectivas do Balanced ScoreCard. Da mesma forma foram apresentadas as semelhanças das duas empresas na visão operacional, que foram obtidas nos questionários respondidos pelos funcionários. Todas as semelhanças foram separadas pelas perspectivas do Balanced ScoreCard.

As semelhanças encontradas na visão estratégica foram: consultoria, treinamentos com $100 \%$ dos funcionários, gestores fizeram a pós-graduação, possuem grupos de melhorias, possuem comitê Lean, reuniões semanais e mensais, visitas de benchmarking por pessoas de todas as áreas, implantação das ferramentas Lean, aumento de produtividade, redução de refugo e retrabalho, redução no índice de reclamação, redução dos custos, redução de desperdício e melhor imagem da empresa. Sob a ótica operacional, as semelhanças encontradas foram: reuniões, visitas, grupos de melhorias, treinamento, implantação das ferramentas Lean, desenvolvimento de novos produtos, satisfação dos clientes, melhor imagem da empresa e todas as melhorias resultaram num retorno financeiro positivo.

Por fim, no item 4.5 foi apresentada a análise de como o sistema lean manufacturing impacta na obtenção da vantagem competitiva nas empresas pesquisadas. Todas as semelhanças foram analisadas separadamente por meio das perspectivas do Balanced ScoreCard e, a partir daí, foi realizada uma relação com os critérios de vantagem competitiva definidas por (SLACK, 1993).

As semelhanças encontradas na perspectiva de aprendizagem e crescimento na visão da direção foram relacionadas com os critérios definidos por Slack (1993), conforme segue: consultoria foi relacionada com velocidade e confiabilidade, as semelhanças de pós-graduação, 
grupos de melhorias, treinamento, reunião, bolsa e visitas foram todas relacionadas com o critério de qualidade e o comitê foi relacionado com todos os critérios de qualidade, velocidade, confiabilidade, flexibilidade e custos.

$\mathrm{Na}$ perspectiva de processos internos no nível estratégico, as semelhanças de qualidade na fonte e ferramentas Lean foram relacionadas com todos os critérios definidos por Slack (1993), que são: qualidade, velocidade, confiabilidade, flexibilidade e custos. Mapa de fluxo de valor foi relacionado com velocidade e confiabilidade, quadros de gestão a vista com velocidade, redução de refugo e retrabalho ligado diretamente com custos e, por fim, o aumento de produtividade relacionado com velocidade, confiabilidade e flexibilidade.

As semelhanças encontradas na perspectiva do cliente foram redução no índice de reclamação e foi relacionada com confiabilidade, a melhora da imagem da empresa foi relacionada com confiabilidade e a redução do lead time relacionado com velocidade confiabilidade.

Por fim, a semelhança encontrada na visão estratégica sob a perspectiva financeira foi redução de desperdício ligada ao critério de custos, o aumento de produtividade relacionado com velocidade, confiabilidade e flexibilidade e a semelhança de redução de custos relacionada com o critério de custos.

No nível operacional, as semelhanças encontradas na perspectiva de aprendizado e crescimento foram: grupo de melhoria, treinamento, reuniões e visitas, todas elas relacionadas com o critério de qualidade definido por Slack (1993). Na visão operacional sob a perspectiva de processo a semelhança de implantação das ferramentas do Lean foi relacionada com todos os critérios definidos por Slack (1993), de qualidade, velocidade, confiabilidade, flexibilidade e custos. $\mathrm{Na}$ perspectiva de cliente as semelhanças encontradas foram: melhor imagem da empresa relacionada com o critério de confiabilidade, satisfação do cliente foi ligada com o critério de velocidade e confiabilidade e por último o desenvolvimento de novos produtos foi relacionado com o critério de flexibilidade. E a semelhança encontrada na visão operacional sob a perspectiva financeira demonstra que todas as melhorias implantadas resultaram em um retorno financeiro positivo e foi relacionada ao critério de custos.

Os impactos na obtenção de vantagem competitiva foram definidas a partir da relação entre os critérios de Slack (1993) e as semelhanças encontradas em todas as perspectivas do balanced scorecard tanto na visão estratégica quanto na visão operacional. Algumas semelhanças são mais representativas outras menos, por estarem relacionadas a um número maior dos critérios estabelecidos por Slack (1993). Assim, comentar-se-á as semelhanças que foram consideradas as mais representativas segundo os depoimentos relatados pela Direção das empresas pesquisadas, e pelos funcionários que responderam o questionário operacional. As semelhanças que possuem um maior número de critérios são consideradas as mais importantes para a obtenção de vantagem 
competitiva, o que não descarta a importância daquelas semelhanças assinaladas com menor número de critérios.

Conforme depoimento da Direção, na perspectiva de aprendizado e crescimento a semelhança que teve maior relação com os critérios de vantagem competitiva, logo, teve maior grau de importância foi o comitê Lean. Este item está relacionado com todos os critérios, de qualidade, velocidade, confiabilidade, flexibilidade e custos, por ser responsável pela definição e acompanhamento das estratégias para a implantação do Lean. Em segundo lugar considerou-se a consultoria por ter impactado diretamente nos critérios de velocidade e confiabilidade, por trazer um conhecimento técnico e específico que a organização não possuía e, agilizando o processo de implantação, com mais rapidez e dando credibilidade em todo o processo. São ainda elencados os grupos de melhorias, pós-graduação, treinamentos, visitas, bolsas e reuniões que estão relacionados somente com o critério de qualidade.

Na perspectiva de processos internos a implantação das ferramentas Lean e da qualidade na fonte tiveram maior impacto, segundo a visão da Diretoria, isso, porque se relaciona com todos os critérios para obtenção da vantagem competitiva. A semelhança de aumento da produtividade também se destaca nesta análise, pois, esta relacionada com três critérios (de velocidade, confiabilidade e flexibilidade), sendo assim, considerada como de grande importância para a implantação da filosofia lean. O mapa de fluxo de valor aparece em terceiro lugar no grau de importância, e está relacionada aos critérios de velocidade e confiabilidade. E as semelhanças de gestão a vista e redução de refugo / retrabalho foram relacionados a apenas um critério que foi velocidade e custos respectivamente. Mesmo com menos representatividade todas têm seu grau de importância e contribuem para o melhor desempenho da empresa.

As semelhanças encontradas na perspectiva de clientes foram redução do lead time, que teve maior contribuição no processo de implantação da filosofia lean, pois, está relacionada com dois critérios para obtenção da vantagem competitiva que são velocidade e confiabilidade. As semelhanças de redução no índice de reclamação e melhor imagem da empresa foram relacionadas apenas com o critério de confiabilidade.

Na visão da Direção a semelhança aumento da produtividade na perspectiva financeira teve maior peso e está ligada aos critérios de velocidade, confiabilidade e flexibilidade. A eliminação dos desperdícios e redução dos custos apesar de estar relacionada somente a um critério também tem sua devida importância, pois, afeta diretamente o critérios de custos.

$\mathrm{Na}$ visão operacional, as semelhanças encontradas na perspectiva aprendizado e crescimento: treinamento, grupos de melhorias, reuniões e visitas foram todas relacionadas com o critério de qualidade e tiveram o mesmo grau de importância segundo a classificação dos funcionários das empresas pesquisadas. 
As semelhanças encontradas na perspectiva de processos internos foram à implantação das ferramentas Lean, classificadas como ponto fundamental para o sucesso na implantação do Lean e obtenção dos resultados para alcançar a vantagem competitiva. As ferramentas Lean têm relação direta com todos os critérios definidos por Slack (1993), qualidade, velocidade, confiabilidade, flexibilidade e custos.

Os funcionários consideraram a satisfação do cliente como o mais importante na perspectiva do cliente em relação às semelhanças de desenvolvimento de novos produtos e imagem da empresa. A semelhança de satisfação do cliente foi relacionada com os critérios de velocidade e confiabilidade enquanto que novos produtos e melhor imagem da empresa foram relacionados com flexibilidade e confiabilidade respectivamente.

Por fim, os funcionários que responderam os questionários foram unânimes em afirmar que todas as melhorias realizadas com a implantação do lean sob a ótica da perspectiva financeira resultaram em melhores retornos financeiros e assim, estão relacionadas ao critério de custos.

\subsection{Recomendações gerenciais para as empresas pesquisadas}

Este trabalho teve como objetivo analisar de que forma o Lean impacta na obtenção de vantagem competitiva nas indústrias pesquisadas do setor moveleiro de São Bento do Sul. Todos os resultados obtidos com esta pesquisa de campo servirão para fornecer informações relevantes ao setor moveleiro, bem como outros segmentos da indústria, com o intuito de melhorarem e alavancarem sua performance.

Neste sentido, esta pesquisa pode contribuir com as empresas pesquisadas oferecendo informações gerenciais e sugerindo algumas ações com base nos estudos levantados. De posse dos resultados obtidos, considera-se alguns mais pontos mais relevantes na percepção da Direção e na visão operacional e que seguem como forma de agregar valor ao processo das empresas estudadas.

$\mathrm{Na}$ visão estratégica, as semelhanças que foram consideradas de maior relevância segundo os diretores entrevistados são o comitê lean a qualidade na fonte e a implantação das ferramentas lean, por estarem relacionadas com todos os critérios de vantagem competitiva apresentado por Slack (1993). A consultoria, o aumento da produtividade, redução do lead time, também foram bem conceituadas na visão da Direção, relacionando-se com velocidade, confiabilidade e flexibilidade. Estas semelhanças tiveram impacto direto nas melhorias do processo da empresa, proporcionando melhores resultados no atendimento ao cliente e, conseqüentemente, na redução de custos.

Na visão operacional, a implantação das ferramentas lean teve maior impacto nos resultados obtidos. Segundo os funcionários que responderam aos questionários as ferramentas implantadas tiveram relação direta com todos os critérios de vantagem competitiva, como a velocidade, 
qualidade, confiabilidade, flexibilidade e custos. As semelhanças de desenvolvimento de novos produtos e melhor imagem da empresa, na visão dos funcionários impactam na obtenção da vantagem competitiva por ter mais flexibilidade e dar confiabilidade ao mercado. Todas as semelhanças da perspectiva de aprendizado e crescimento foram relacionadas com a qualidade e todas as melhorias realizadas na perspectiva financeira foram relacionadas com custos, segundo os funcionários.

Esta pesquisa, com os resultados e as informações obtidas será enviada para os gestores das empresas estudadas para que possam servir de suporte ao processo de tomada de decisão e contribuir para a melhoria continua dos processos de lean manufaturing para obtenção de vantagem competitiva.

\subsection{Sugestões para estudos futuros}

Este trabalho está limitado apenas aos critérios de vantagem competitiva apresentado por Slack (1993), por estar diretamente relacionado ao processo de obtenção de vantagem competitiva nas organizações e por uma questão de familiaridade com a abordagem do autor. No entanto, isso não impossibilita a utilização de qualquer outra abordagem, que também seria possível.

Como trabalho futuro também se sugere a utilização de uma escala para avaliação quantitativa dos resultados obtidos, e ainda, a aplicação de métodos estatísticos para analisar os resultados, bem como critérios adotados por outras ferramentas diferentes do BSC.

Poder-se-ia continuar o mesmo estudo, utilizando um referencial teórico empírico mais amplo, estendendo-o a outras empresas do setor a fim de conhecer as diferentes leituras do processo de implementação do Lean Manufacturing. O estudo poderia ir ainda mais além, com a tentativa de traçar um perfil dos executivos e funcionários ligados a implementação do Lean, com a finalidade de estabelecer um padrão cognitivo que reflita o sucesso na obtenção de vantagem competitiva. Com isso, uma futura pesquisa iria orientar os dirigentes das empresas e ajudaria na construção de ferramentas úteis para o processo de tomada de decisão proporcionando maior vantagem competitiva para as organizações.

Alguns aspectos deste trabalho merecem uma maior investigação e, conseqüentemente, também são apresentados como sugestão para estudos futuros. Um desses aspectos refere-se à utilização dos resultados da pesquisa para a elaboração de um modelo voltado para a obtenção de vantagem competitiva por meio das ferramentas Lean. Ou aspecto que pode ser considerado é a utilização do modelo para o estudo de aspectos específicos relacionados ao Lean. E, por fim, sugere-se um direcionamento da proposta de obtenção de vantagem competitiva que considere as fases da implementação do Lean nas organizações e as características dos executivos e/ou funcionários. 


\begin{abstract}
In a globalized economy, the survival of organizations depends on their ability and flexibility to innovate and effect continuous improvements. In this context, organizations have searched for new management tools to direct them towards greater competitiveness through quality and productivity. One such tool is Lean Manufacturing. In this work, we developed a study aiming to analyze the impacts of the implementation of Lean Manufacturing in obtaining competitive advantage in two companies in two furniture companies, namely Artefama and Rudnick, which are located in the São Bento do Sul region. To reach the proposed goals, qualitative phenomenological field research was conducted in both companies, with managers and production workers taking part in the research. The following were the main results obtained in the: in the strategic vision and according to the directors interviewed, the most important similarities are the Lean Committee, the quality at source, and the implementation of Lean tools, for they are related to all the criteria for competitive advantage presented by Slack (1993). The consultancy, increased productivity, and lead time reductions were also positively regarded by the direction, being related to speed, reliability and flexibility. In the operational vision, the similarities in the development of new products e the bettered company image contribute to the obtention of competitive advantage, offering the market more flexibility and reliability. All the similarities in learning and growth were related to quality and all the financial improvements were related to costs, according to employees. It is concluded, therefore, that some tools lean impact significantly the competitive advantages.
\end{abstract}

Key-words: lean manufacturing; competitive advantage; BSC.

\title{
Referências
}

ANTUNES, J.A.V. A lógica das perdas nos Sistemas de Produção: uma análise crítica. Anais do XIX ENANPAD, João Pessoa [s.n.], 1 CD-ROM p.357-371, 1995.

ASSOCIAÇÃO BRASILEIRA DAS INDÚSTRIAS DO MOBILIÁRIO (Abimóvel). Panorama do setor moveleiro no Brasil: informações gerais. São Paulo, 2005. 75p. Disponível em: <http://www.abimovel.com>. Acesso em: 19 nov. 2005 .

CORRÊA, H. L.; GIANESI, I. G. N.. Just In Time, MRP II e OPT: Um enfoque estratégico. São Paulo: Atlas, 1996.

CUSUMANO, M. A. The Limits of Lean. Sloan Management Review, 1994, p.27-32.

DAVENPORT T. H.; PRUSAK L.. Conhecimento Empresarial: como as organizações gerenciam o seu capital intelectual. Rio de Janeiro: Campus, 1998.

DIAS, F. T.; FERNANDES, F. C. F.; FILHO, M. G. Uma metodologia baseada em indicadores de desempenho para avaliação da implantação da manufatura enxuta: proposta e estudo de caso. Revista Gestão Industrial v.4, n.2, p.104$122,2008$.

cross ref

EPSTEIN, M.; MANZONI, J. F. Implementing corporate strategy: from tableaux de bord to balanced scorecards. European Management Journal, v. 16, n. 2, p. 190-203, 1998.

FARIA a. C.; VIEIRA v. S.; PERETTI, 1. C. Redução de custos sob a ótica da manufatura enxuta em empresa de autopeças. Revista Gestão Industrial v.08, n.2, p.186-208, 2012.

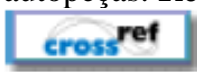

FLEURY, A. C. C.; FLEURY, M. T. Estratégias competitivas e competências essenciais: perspectivas para a internacionalização da indústria no Brasil. Revista Gestão e Produção v.10, n.2, p.129-144, ago. 2003.

GARCIA, R.; MOTTA, F. G. Móveis residenciais de madeira: relatório setorial preliminar FINEP. Disponível em: <http://www.finep.gov.br/PortalDPP/relatorio_setorial/>. Acesso em: 01 mar, 2007. 
HINES, P.; TAYLOR. D. Going lean: A guide to implementation. Cardiff, UK: Lean Enterprise Research Center, 2000.

HITT, M. A.; IRELAND, D. R.; HOSRISSON, R. E. Administração estratégica. São Paulo: Thomson, 2002.

JAMES-MOORE, S.M.; GIBBONS, A. (1997). Is lean manufacture universally relevant? An investigative methodology. International Journal of Operations and Production Management, v. 17, nº 9, p. 899-911.

cross ref

KAPLAN, R. S.; NORTON, D. P. Putting the balanced scorecard to work. Harvard Business Review. v. 71, n. 5, p. 134-142, sep./oct. 1993.

KAPLAN, R. S.; NORTON, D. P. Using the balanced scorecard as a strategic management system. Harvard Business Review, v. 74, n. 1, p. 75-85, jan./feb. 1996.

KAPLAN, R. S.; NORTON, D. P. Building a Strategy-Focused Organization. Harvard Business School Press, 1999.

KAPLAN, Robert S.; NORTON, David P. Organização orientada para a estratégia: como as empresas que adotam o balanced scorecard prosperam no novo ambiente de negócios. Rio de Janeiro: Campus, 2000.

KRAFCIK, F. Triumph of the Lean Production System. Fall: Sloan Management Review, 1988.

MACEDO, M. TV Digital Interativa e Gestão do Conhecimento Organizacional. 2008. 202f. Tese (Doutorado em Engenharia e Gestão do Conhecimento) - Universidade Federal de Santa Catarina, Florianópolis, 2008.

MONDEN, Y., Toyota Production System: an integrated approach to Just-in-Time. Norcross - Georgia: EMP Books, 1998.

OHNO, T.; MITO, S. Just-in-time for today and tomorrow. Cambridge, Massachusetts: Productivity Press, 1988.

PANIZZOLO, R. Applying the lessons learned from 27 lean manufacturers. The relevance of relationships management. Production Economics, março, 1998.

PEREIRA, A.F; et al. Prospecção e diagnóstico como subsídio para intervenção em empresas do setor moveleiro de Ubá - MG. In: $7^{\circ}$ Congresso Brasileiro de Pesquisa e Desenvolvimento em Design. Anais. Curitiba, PR, 2006.

PORTER, M. E. Competição: Estratégias Competitivas Essenciais. 6. Edição. São Paulo: Editora Campus Ltda, 1999.

PORTER, M. E. Vantagem competitiva: criando e sustentando um desempenho superior. Rio de Janeiro: Campus, 1989, p. 1-53.

PRADO, R. V. B.; PRADO, M. V. Brasil Móveis / Relatório Setorial da Indústria Móveis do Brasil. São Paulo: IEME (Instituto de Estudos e Marketing Industrial Ltda), 2007.

RITZMAN, L. P.; KRAJEWSKI, L. J. Administração da produção e operações. São Paulo: Prentice Hall, 2004.

SHAH, R.; WARD, P. T. Lean Manufacturing: Context,Practice Bundles and Performance. Journal of Operations Management. UK: Elsevier, 2003.

SHANK, P. New skills for a new field: What you need to know to be an eLearning expert. Online learning, 2002.

SHINGO, S. O Sistema Toyota de Produção do ponto de vista da engenharia de produção. Porto Alegre: Ed. Bookman, 1996.

SKINNER, W. Manufacturing: the missing link in corporate strategy. Harvard Business Review. Boston, May/June, 1969, p. 136-144.

SLACK, N. Vantagem competitiva em manufatura: atingindo competitividade nas operações industriais. São Paulo: Atlas, 1993, 
SOARES, H. S. D. G. Globalização do sistema de manufatura baseado nas estratégias de melhoria contínua em uma empresa do setor automotivo. São Paulo, 121 p. 2007. Trabalho de conclusão de curso (Mestrado

Profissionalizante em Engenharia Automotiva) - Escola Politécnica da Universidade de São Paulo.

STOLLENWERK, M. F. L. Gestão do Conhecimento, Inteligência Competitiva e Estratégia Empresarial: em busca de uma abordagem integrada. In: I Workshop Brasileiro de Inteligência Competitiva. Semana do Conhecimento. Anais. Rio de Janeiro: PETROBRAS. FINEP. SENAI/CIET.18 a 22 de outubro de 1999.

TEIXEIRA FILHO, J. Gerenciando Conhecimento: como a empresa pode usar a memória organizacional e a inteligência competitiva no desenvolvimento de negócios. Rio de Janeiro: Editora SENAC, 2000.

WOMACK, J. P. et al. A Máquina que Mudou o Mundo. Rio de Janeiro: Campus, 1992.

WOMACK, J. P.; JONES, D. T. Lean Thinking: Banish Waste and Create Wealth in your corporation. New York: Simon \& Schuster, 1996.

WOMACK, J. P.; JONES, D. T. A mentalidade enxuta nas empresas. Rio de Janeiro: Campus, 1998.

\section{Dados dos autores:}

Nome completo: Marcelo Macedo

Filiação institucional: Universidade Federal de santa Catarina

Departamento: Engenharia do conhecimento

Função ou cargo ocupado: Professor/pesquisador.

Endereço completo para correspondência: Florianópolis, Campus Universitário Reitor João Da

Vinci Ferreira Lima, Trindade - Florianópolis - Santa Catarina - Brasil, CEP: 88040-900 -

Departamento de Engenharia do Conhecimento.

Telefones para contato: 48- 8405-9091

e-mail: marcelomacedo@egc.ufsc.br

\section{Nome completo: Edson Possamai}

Filiação institucional: Instituto Superior Tupy/SOCIESC

Departamento: Pós-Graduação

Função ou cargo ocupado: Gestor Comercial

Endereço completo para correspondência (bairro, cidade, estado, país e CEP):

Aventureiro; Joinville, SC; Brasil - CEP 89225540.

Telefones para contato: 47- 9181- 8759 / 47 - 3437 - 4894

e-mail: edson.possamai@ sociesc.org.br

Enviado em: 12/12/2012

Aprovado em: 10/06/2013 